\title{
STRUCTURAL AND MAGNETIC CARACTERIZATION OF COMPOUNDS Y(Cr,Fe)O3 OBTAINED BY CO-PRECIPITATION METHOD
}

\author{
Fabian, F. A. ${ }^{1}{ }^{*}$; Jesus, J. R. ${ }^{1}$; Pedra, P. P. ${ }^{1}$; Duque, J. G. S. ${ }^{2}$; Meneses, C. T. ${ }^{2}$ \\ ${ }^{1}$ Universidade Federal de Sergipe. Departamento Física, São Cristóvão, Sergipe, Brazil \\ ${ }^{2}$ Universidade Federal de Sergipe. Departamento Física, Itabaiana, Sergipe, Brazil \\ *fernandafabianro@gmail.com
}

Oxides perovskite $\left(\mathrm{ABO}_{3}\right)$ have been studied in order to understand the structural, mechanical, electrical and magnetic properties that these materials exhibit. In this compounds the magnetic properties are usually determined by the cation of B-site, and therefore the substitution this site with transition metals different leads to a variety of phenomena. In this work were obtained $\mathrm{YFe}_{1-\mathrm{x}} \mathrm{Cr}_{\mathrm{x}} \mathrm{O}_{3}(0 \leq \mathrm{x} \leq 1)$ using the method of chemical co-precipitation. The X-ray diffraction measurements allied Rietveld refinement confirm formation of the crystalline phase of all concentration identified as orthorhombic structure. In this results a shift of the peaks and reducing the volume by increasing the chromium concentration was observed. The measurements of magnetization as a function temperature show that the studied systems are antiferromagnetic accompainied by a weak ferromagentism. These results indicate the system has a strong dependence of the Neel temperature $\left(\mathrm{T}_{\mathrm{N}}\right)$ with concentration of $\mathrm{Cr}$ in matrix. In addition, the reverse magnetization phenomenon was observed for the $\mathrm{x}=0,5$ concentration. The measurements of magnetization as a function field at room temperature show that the regions of high field behavior antiferromagnetic one for all samples is observed. In the region of low field linear behavior is observed for samples with higher chromium concentration, and the samples with higher iron concentration is observed the presence of a small hysteresis loop due to weak ferromagnetic component. 